\title{
Monitoring requirements in patients with acute myocardial infarction
}

\author{
A. A. JeNNifER AdgeY \\ Research Fellow
}

\author{
J. F. PANTRIDGE \\ Physician-in-Charge
}

\begin{abstract}
Summary
The majority of deaths from myocardial infarction occur soon after the onset of symptoms. The mobile scheme described allows intensive care to commence in the patient's own home or at the site of infarction and thus reduces the interval between the onset of symptoms and the initiation of intensive care. Monitoring is continued during transport and following admission to the hospital coronary care unit.

The major impact of therapy on the mortality from acute myocardial infarction will result from the detection and correction of rhythm disturbances.
\end{abstract}

THE MAJORITY of deaths from acute myocardial infarction occur soon after the onset of symptoms. Sixty per cent of the deaths occur within $1 \mathrm{hr}$ of the onset of symptoms (Yater et al., 1948; Bainton \& Peterson, 1963). A survey in Belfast in 1965 showed that over $40 \%$ of the deaths from acute myocardial infarction occur within the first hour (Fig. 1, curve A) (McNeilly \& Pemberton, 1968). The majority of

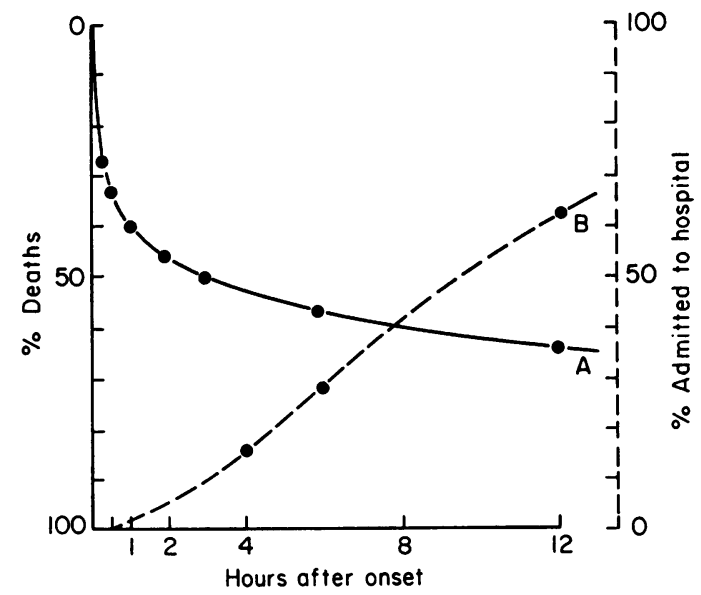

FIG. 1. The time-relationship of deaths from acute myocardial infarction and the admission pattern to hospital coronary care units.

Curve A constructed from the data of McNeilly \& Pemberton (1968).

Curve B constructed from the data of McDonald (1968). the deaths from myocardial infarction occur outside hospital (Spiekerman et al., 1962; Kuller, Lilienfeld \& Fisher, 1966), and there is little doubt that most of these deaths are due to ventricular fibrillation. Yet the median time between onset of symptoms and admission to a hospital coronary care unit is more than 8 hours (Fig. 1, curve B) (McDonald, 1968).

The Belfast study (McNeilly \& Pemberton, 1968) showed that of 901 individuals who had a fatal coronary attack in the year surveyed, only 414 reached hospital; 109 were dead on arrival. Experience in North London (Nixon, 1968) showed that of the patients who died within the first $24 \mathrm{hr}$ of myocardial infarction, $47 \%$ did so before an ambulance arrived; $13 \%$ died during transit and only $40 \%$ of the deaths in the first 24 hours occurred in hospital.

Since the majority of deaths occur early and since there is usually a considerable delay in hospital admission it would seem that although hospital coronary care units reduce the hospital mortality, such units will not have a profound effect on the overall mortality. If the greater part of the delay in hospital admission resulted from delay in the patient seeking medical help, then little could be done about the early high mortality. However, the data of McNeilly \& Pemberton indicate that patient delay is not the major factor. They found that the median time between the onset of symptoms and request for medical help was for males $1 \mathrm{hr} 17 \mathrm{~min}$ and for females $1 \mathrm{hr} 6 \mathrm{~min}$. Many other factors are involved in the delay in the initiation of intensive care. The family doctor may be unaware of the high risk of sudden and preventable death in the patient with an apparently mild coronary attack. The ordinary ambulance service may not always be capable of dealing with the call immediately. Much time may elapse between the patient's arrival at the hospital casualty or admission area and his transfer to a coronary care unit. It was thought possible to remove all causes of delay apart from that due to the patient's failure to seek immediate medical aid. It seemed that this patient delay might diminish with increasing public awareness of the importance of seeking medical help promptly. 


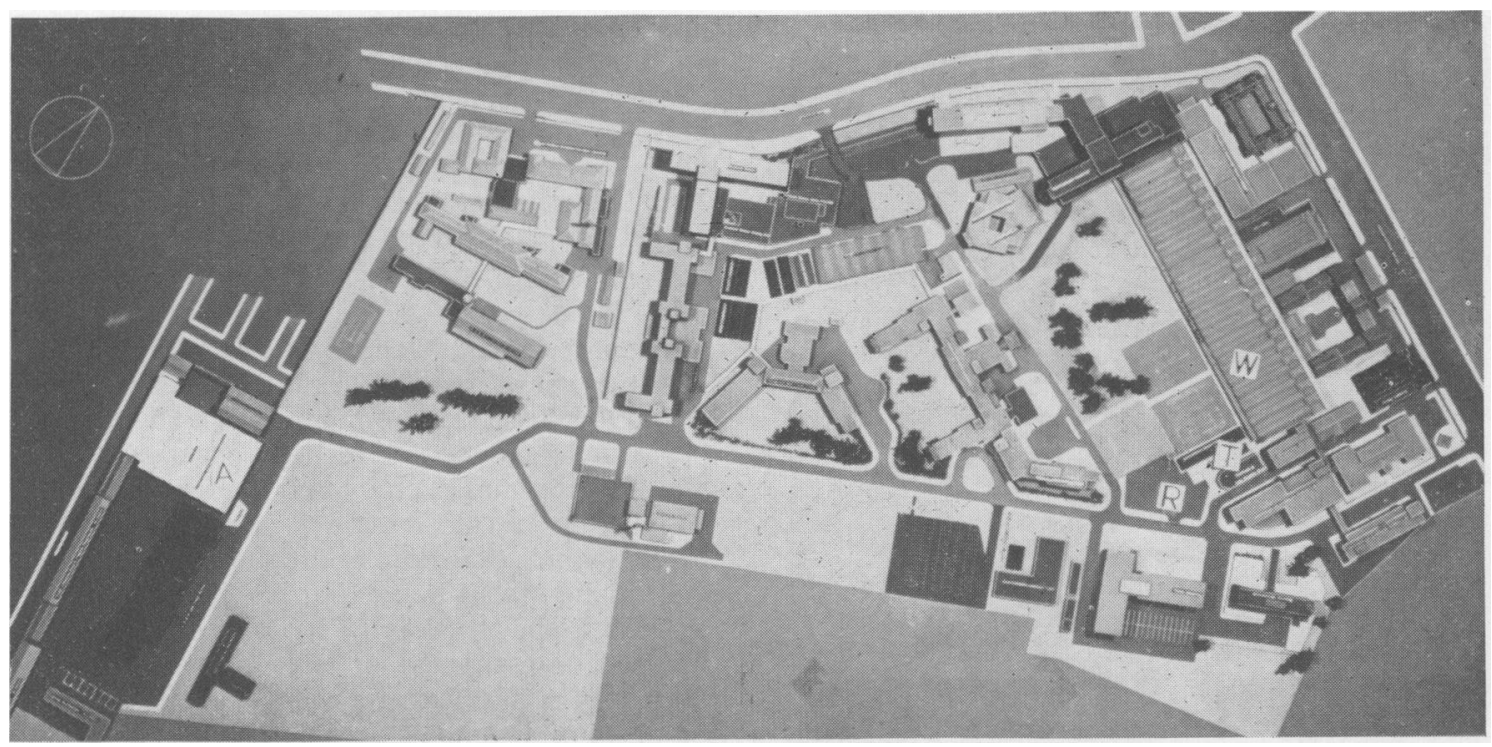

Fig. 2. Plan of Hospital Area. A: Ambulance depot

When the mobile unit commenced operation in Belfast on 1 January, 1966 (Pantridge \& Geddes: 1966,1967 ) the family doctors in the city (population 550,000 ) were informed of the facts concerning early deaths and were given instruction in resuscitation methods. The family doctors were given a special telephone number. Calls to this number get to the coronary care ward (Fig. 2, W) directly and thus delays at the hospital telephone exchange are avoided. A short-wave radio system is used to ensure that a junior doctor receives the call immediately. The main ambulance depot for the area is located in the hospital grounds (Fig. 2, A). When ambulance control is activated an ambulance proceeds to point R (Fig. 2). When it arrives there, a junior doctor and a nurse from the coronary care unit will have reached this point. The team is on its way within 2 min of the receipt of the signal from the family doctor. The ambulance carries the usual equipment found in a hospital coronary care unit, monitoring and resuscitation equipment including a batteryoperated DC defibrillator and pacing catheters. All equipment is portable. When the team reaches the patient in his own home or at the site of attack he is under the same intensive care conditions that obtain in a hospital coronary care unit. Fifty per cent of the patients are reached within 10 min of receipt of the call from the family doctor.

The major objective of a mobile coronary care unit as of coronary care units in hospitals, is the prevention of death from rhythm disturbance since it is likely that the majority of coronary deaths occurring soon after the onset of symptoms result from ventricular fibrillation. The family doctor may call for the

\section{R: Rendezvous point $\quad T$ : Telephone exchange $\quad W$ : Ward.}

mobile unit immediately, and before he has seen the patient, if he considers that a message he has received indicates the probability of myocardial infarction. The majority of calls come from the family doctors. A proportion of the calls do however come from the general public, usually because the patient or his relatives are unable to contact the general practitioner. The screening of such calls is undertaken by the coronary care unit personnel. If the family doctor reaches the patient before the mobile unit, he will initiate immediate therapy for the relief of pain and for bradyarrhythmia or ventricular dysrhythmia. The practitioners have been given precise instructions as to the therapy to be employed in such circumstances. When the team arrives, electrocardiographic monitoring is commenced and therapy continued in the patient's own home or at the site of the attack. The patient is not moved until a stable rhythm is established.

It seems likely that in many situations initial monitoring can be carried out by the general practitioner and so we have been developing a small, inexpensive oscilloscope (Fig. 3). A tele-equipment Type S51B oscilloscope weighing $14 \frac{1}{2} \mathrm{lbs}$ with a long glow phosphor screen is used as shown here. A small ECG amplifier is built utilizing linear operational integrated circuits. This high-input impedance amplifier has a lower 3DB point at $1 \mathrm{cycle} / \mathrm{sec}$ and an upper limit 3DB point at $100 \mathrm{cycles} / \mathrm{sec}$. For safety requirements the ECG amplifier is transformerisolated from the oscilloscope circuit and Zener diodes are used to limit the power supply output. A defibrillation protection circuit is also fitted to the input circuit. This protection circuit is fitted to all 


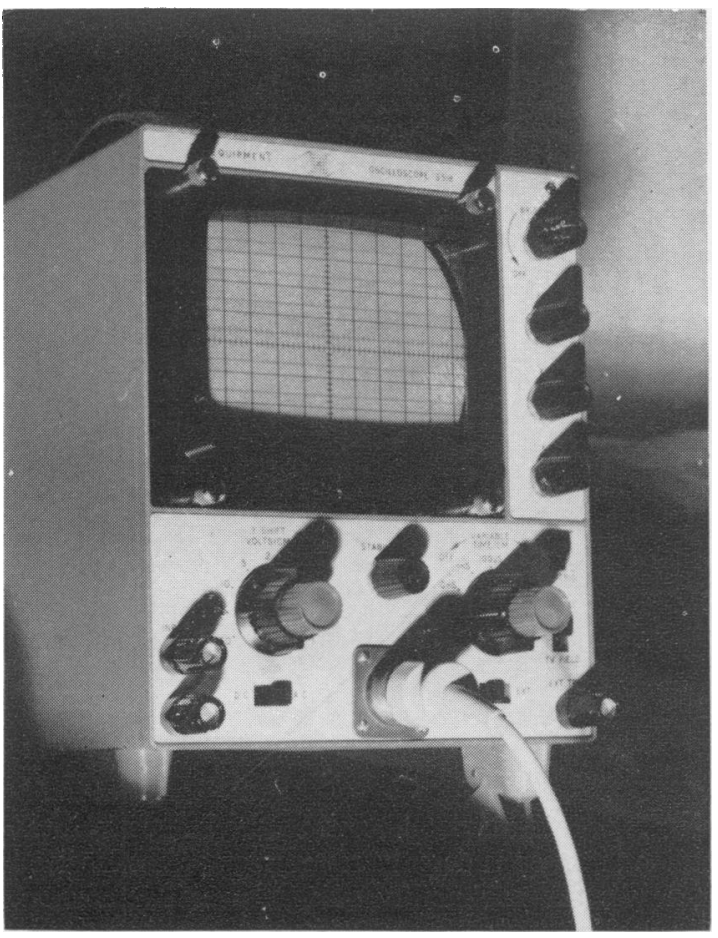

FIG. 3. Portable oscilloscope for use by the family doctor. our monitoring equipment. This monitor gives a $5^{\prime \prime}$ visual display and can be produced for $£ 60$.

Monitoring and therapy are continued during transport to the hospital coronary care unit (Fig. 4) thus removing the risk of arrhythmic death during transit. Haste or fuss during transit is most carefully avoided. There has been no coronary death during transport in the period of nearly 4 years of the unit's operation.

Within the period 1 January, 1966 and 31 October, 1969, there have been 2529 calls for the mobile unit and during this period 1072 patients with indubitable myocardial infarction have been managed by the unit. The diagnosis of infarction was considered established when (a) there was indubitable electrocardiographic evidence of recent infarction or sequential ST or $\mathrm{T}$ wave changes accompanied by significant and transient rise in serum glutamic oxalacetic-transaminase or (b) left bundle branch block with similar enzyme changes. The time after the onset of symptoms at which the 1072 patients came under intensive care is shown in Fig. 5. $265(25 \%)$ came under intensive care within $1 \mathrm{hr}$, $553(52 \%)$ within $2 \mathrm{hr}$ and $803(75 \%)$ within $4 \mathrm{hr}$. Fig. 6 shows that over the $3 \frac{1}{2}$ year period increasing numbers of patients have come under intensive care early.

Bradyarrhythmia is frequent among those seen early. Forty-six per cent of patients with posterior

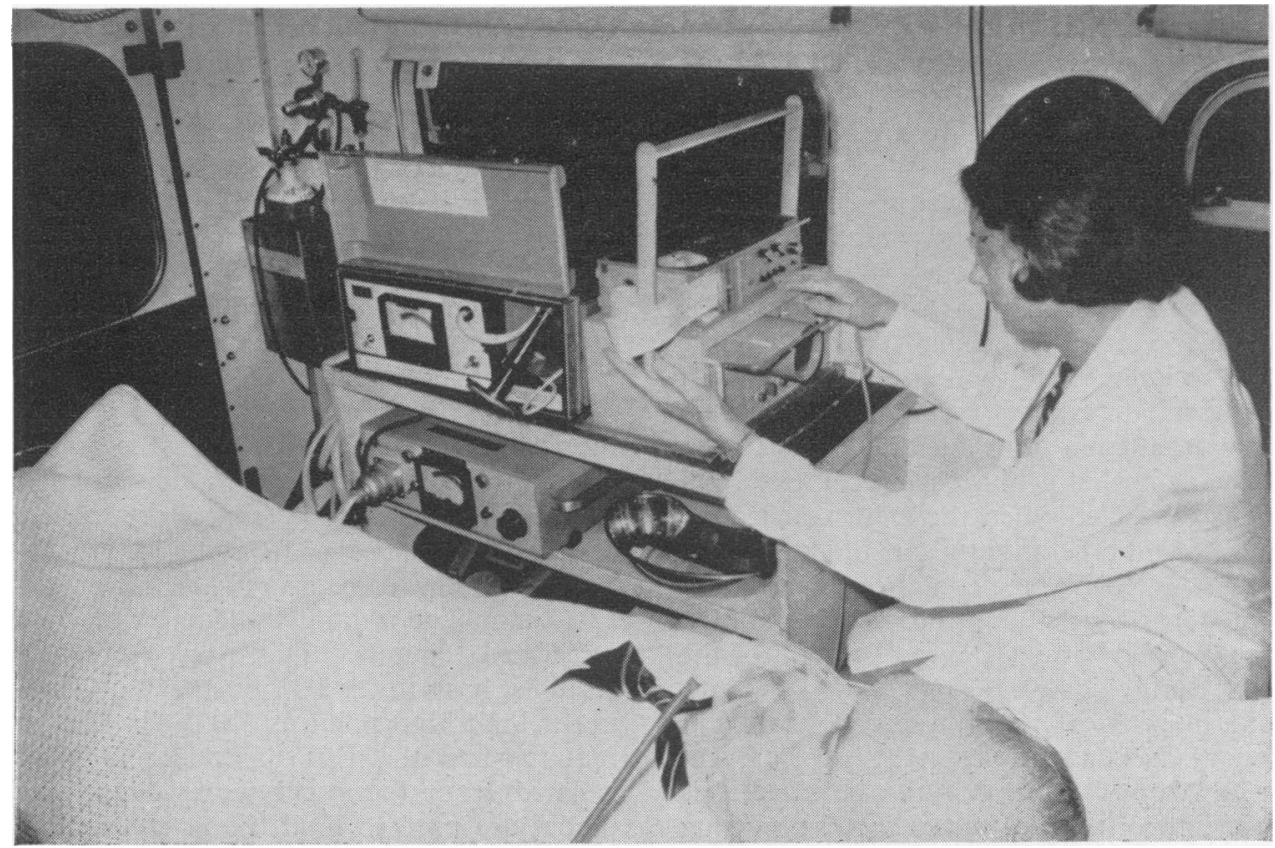

FIG. 4. Mobile coronary care ambulance. 


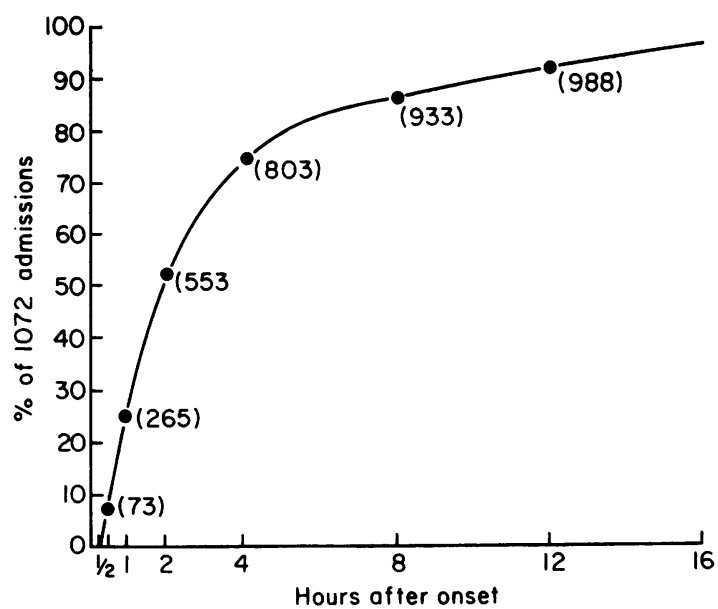

Fig. 5. The time after the onset of symptoms at which 1072 patients with acute myocardial infarction managed by the mobile intensive care unit came under intensive care.

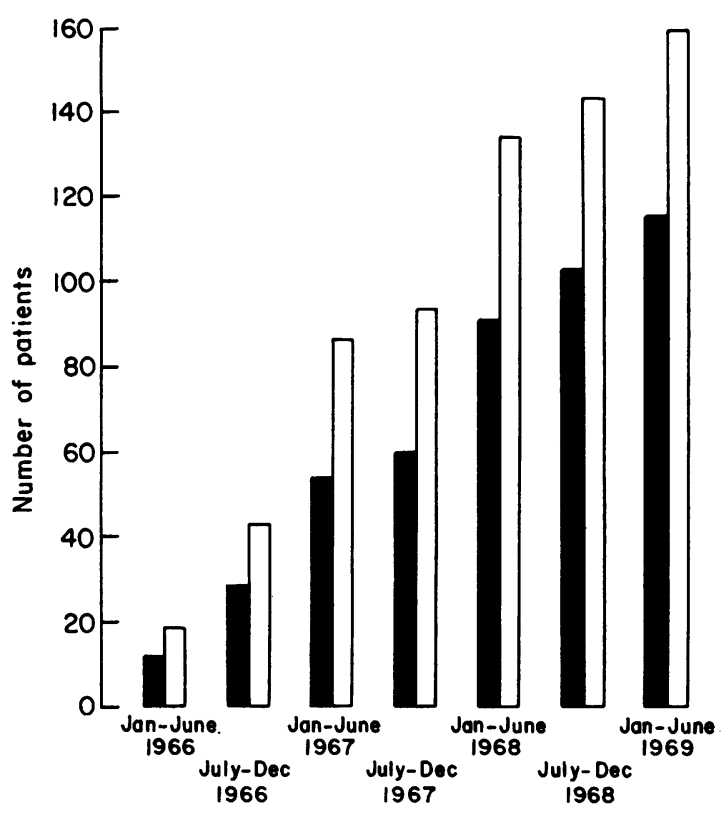

Fig. 6. Number of patients who came under intensive care early, in 6-monthly periods since 1 January 1966.

Black columns seen within $2 \mathrm{hr}$ of onset of symptoms.

White columns seen within $4 \mathrm{hr}$ of onset of symptoms.

myocardial infarction seen within the first hour show bradyarrhythmia i.e. sinus or nodal bradycardia or atrioventricular block second degree or complete at the initial examination. It is of interest that AV block may result from intense early vagal discharge and may be corrected by atropine (Adgey et al., 1968). It is likely that bradyarrhythmia is an important precursor of ventricular fibrillation. Experimental evidence indicates that the fibrillation threshold is significantly lower at slow heart rates. Early bradyarrhythmia may be an important factor in the deaths that occur during ambulance transport, in emergency rooms or in casualty departments of hospitals and in transit between admission areas and coronary care units. A mobile unit allows bradyarrhythmia to be corrected in the patient's home or at the site of the attack prior to transport to hospital. An important feature of a mobile unit is that the patient is admitted directly from the ambulance to the hospital coronary care unit thus avoiding the dangers and delays of hospital casualty departments and admission areas.

The hospital mortality among those patients seen early is less than among those seen later. Thus the hospital mortality of those seen within the first hour who are aged 70 years and less is $11.52 \%$. It is likely that in some cases cardiogenic shock is precipitated by rhythm disturbance and that the early correction of bradyarrhythmia or tachyarrhythmia will prevent such shock. The incidence of cardiogenic shock among those patients seen early has been lower than that usually reported from coronary care units. Thus among patients with a first myocardial infarction seen within the first hour and aged 70 years and less, cardiogenic shock complicated the infarction in only 5 of $165(3.03 \%)$.

Fig. 7 indicates the likely effect of mobile coronary care on the mortality from myocardial infarction.

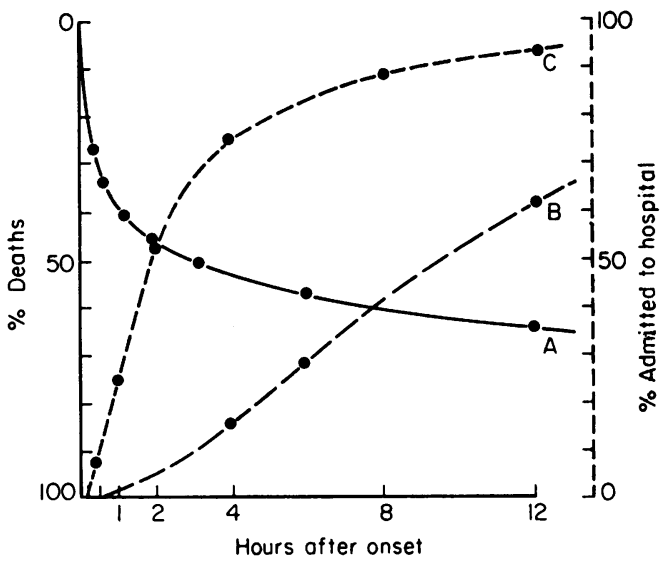

FIG. 7. The possible effect of mobile intensive care on the mortality from acute myocardial infarction.

Curve A shows that the majority of deaths occur early, more than $40 \%$ within the first hour (McNeilly \& Pemberton, 1968).

Curve B constructed from the data of McDonald (1968) shows the usual admission pattern to coronary care units; only $16 \%$ of the patients are admitted within $4 \mathrm{hr}$.

Curve $\mathrm{C}$ constructed from 1072 patients admitted by the Belfast mobile unit; $75 \%$ of patients come under intensive care within $4 \mathrm{hr}$. 
Curve A constructed from the data of McNeilly \& Pemberton (1968) indicates that $40 \%$ of the deaths occur in the first hour. Curve $B$ indicates the usual admission pattern constructed from the data of McDonald (1968) and shows that only $16 \%$ reach a coronary care unit within $4 \mathrm{hr}$. Curve $\mathrm{C}$ is the pattern obtained by the mobile coronary care unit in Belfast: $25 \%$ come under intensive care within $1 \mathrm{hr}$, $52 \%$ within $2 \mathrm{hr}$ and $75 \%$ within $4 \mathrm{hr}$. It is likely that many arrhythmic deaths among patients who fall between curves $B$ and $C$ will be prevented.

While the objective of a mobile unit is to get the patient under intensive care early, correct rhythm disturbance and prevent the development of ventricular fibrillation, this cannot of course always be achieved. Ventricular fibrillation may be the presenting manifestation of ischaemic heart disease. Furthermore, anti-arrhythmic agents are less effective in preventing the ventricular dysrhythmias that occur immediately after the onset of coronary occlusion. However, experience with a mobile unit has shown that the correction of ventricular fibrillation outside hospital is a practical proposition (Adgey et al., 1969; Pantridge \& Adgey, 1969). It is of interest that in fifty-three patients ventricular fibrillation was successfully corrected outside hospital, of whom there are now thirty-seven long-term survivors. Twenty-one developed ventricular fibrillation in their homes, twelve in transit and twenty in various other situations, e.g. at work or in the street. Since correction of ventricular fibrillation outside hospital is possible, further impact on the very high early mortality from acute myocardial infarction should result when mobile units are supported by first-aid training programmes in resuscitation methods.

A portable DC defibrillator is an essential part of the equipment of a mobile unit. The first portable DC defibrillation equipment was developed in this hospital (Pantridge \& Geddes, 1966). A portable defibrillator should be of light weight and it must be reliable. The problem with battery-operated defibrillators has been the breakdown of the diodes which form part of the high voltage ladder for charging the capacitor of the defibrillator. The energy required being $400 \mathrm{~J}$ and from the formula JOULES $=\frac{1}{2} \mathrm{cv}^{2}$ it can be seen that the larger the capacitor the smaller the voltage required to charge it from battery source or the smaller the capacitor the larger the voltage. Most manufacturers seem to have selected a $16 \mu \mathrm{F}$ capacitor which requires to be charged to $7 \mathrm{Kv}$ to give $400 \mathrm{~J}$. One must also consider the size of the inductance coil which determines the shape of the $4 \frac{1}{2} \mathrm{msec}$ wave. After selecting the capacitor size, voltage charge and inductance coil a more reliable high voltage ladder must be produced to charge the capacitor from battery source.

The Belfast mobile coronary care unit is staffed by junior doctors and nurses trained in coronary care. However, we are well aware that in non-teaching hospitals it may not be possible to have a doctor travelling in the mobile unit. We have therefore developed in conjunction with the Marconi Company a radio-telemetry system for the transmission of the ECG from the site of infarction. This we think will allow junior medical and paramedical personnel to transmit the ECG to the central coronary care unit and receive directions from that unit by voice link through the radio system. We found it possible to transmit the ECG over a distance of 10 miles. Fig. 8 illustrates the system. The signal from the patient is taken through a pre-amplifier and voltage control oscillator, as shown in Fig. 9 sited above the ECG pen recorder and oscilloscope. A Pye 5 watt radio system provides an amptitude-modulated radio link with the hospital. The signal is received in the hospital ward where it is discriminated and filtered. The electrocardiogram is then displayed on an oscilloscope and recorded by the pen recorder (Fig. 10). In Fig. 11 is shown the simultaneous recording of the ECG. The upper tracing was taken at the site of attack and the lower tracing was recorded in the hospital coronary care unit-some 5 miles distant.

The remainder of this communication deals with monitoring in the hospital. It has been shown
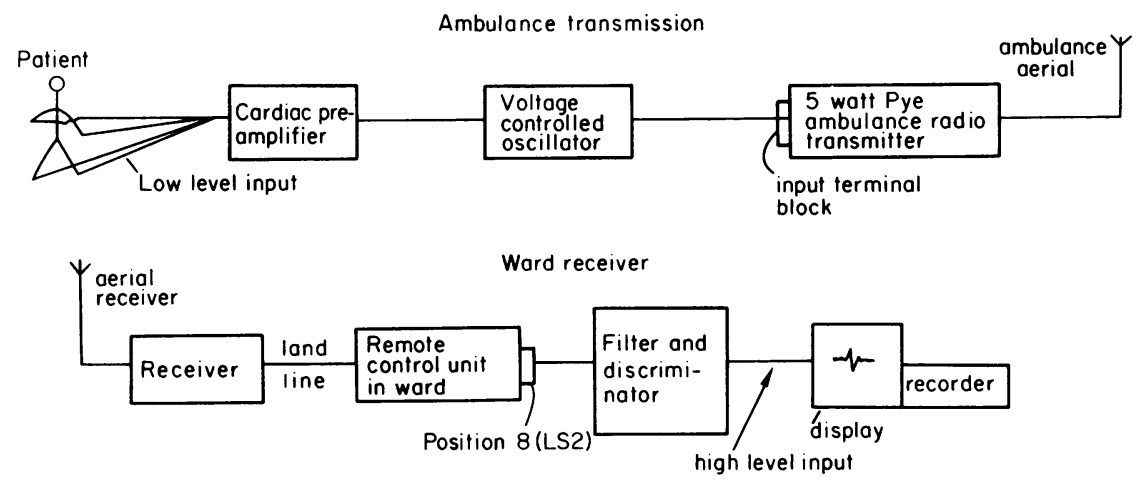

FIG. 8. Radio-telemetry system for the transmission of the ECG. 


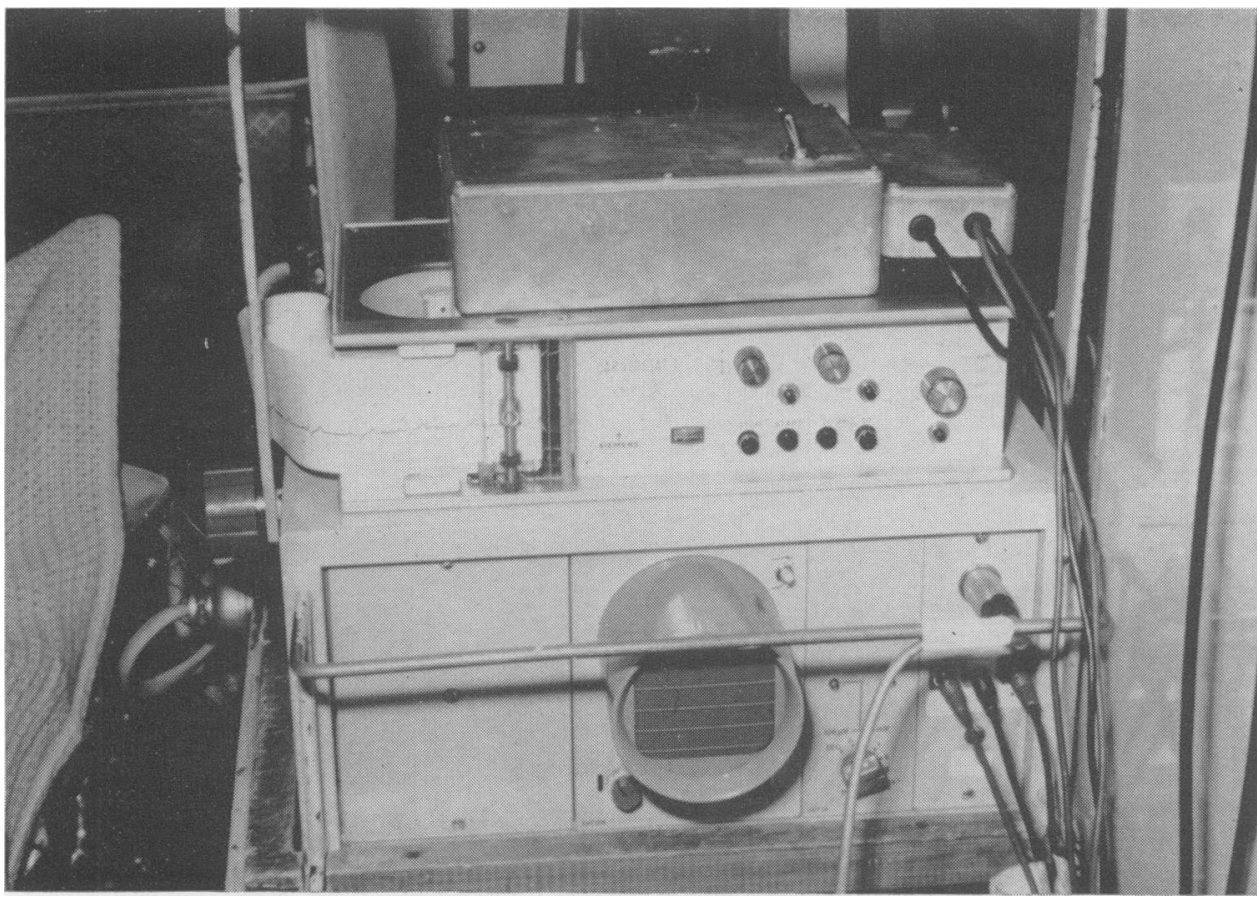

FIG. 9. Pre-amplifier and voltage control oscillator sited above the ECG pen recorder.

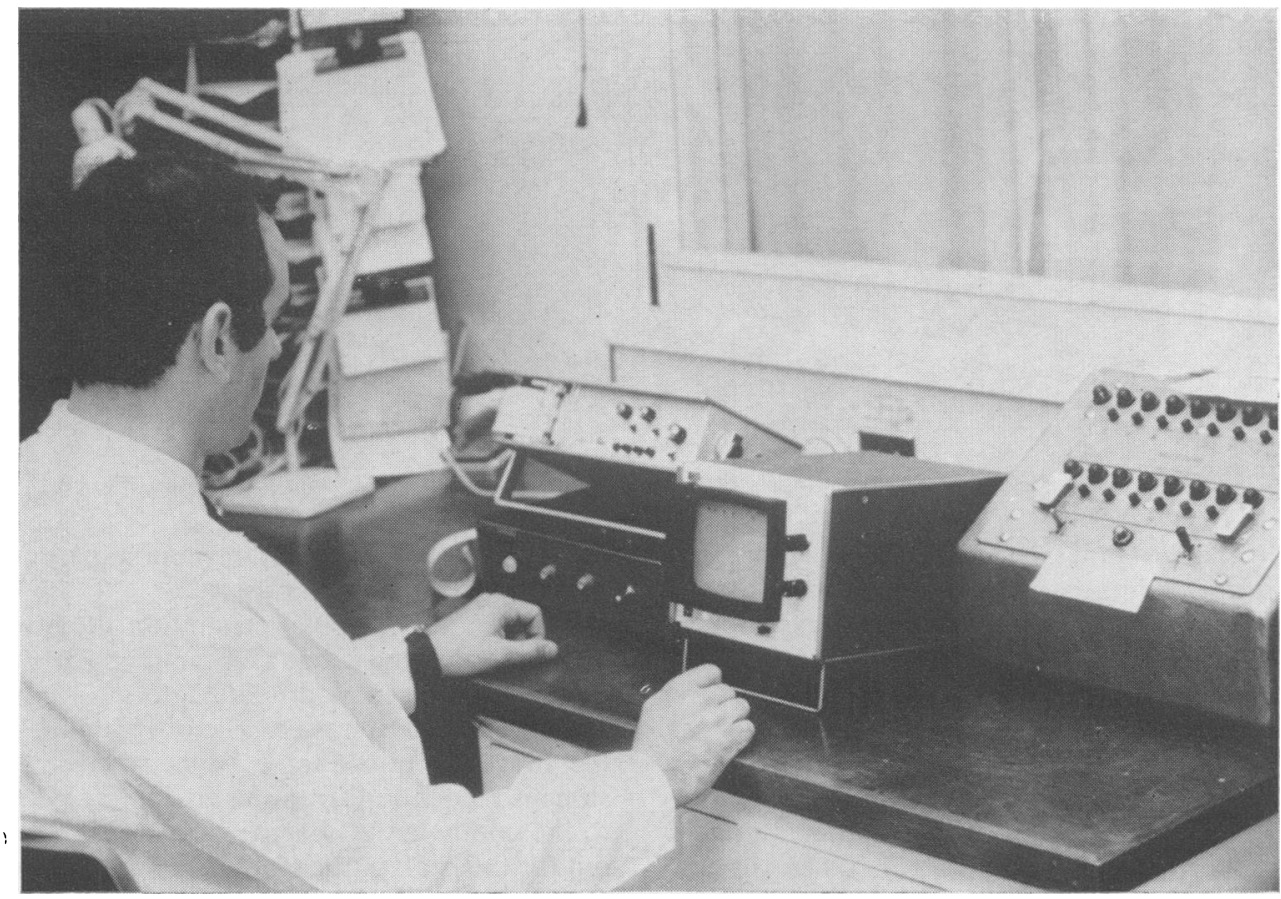

FIG. 10. Filter and discriminator with ECG oscilloscope and pen recorder in the hospital coronary care unit. 


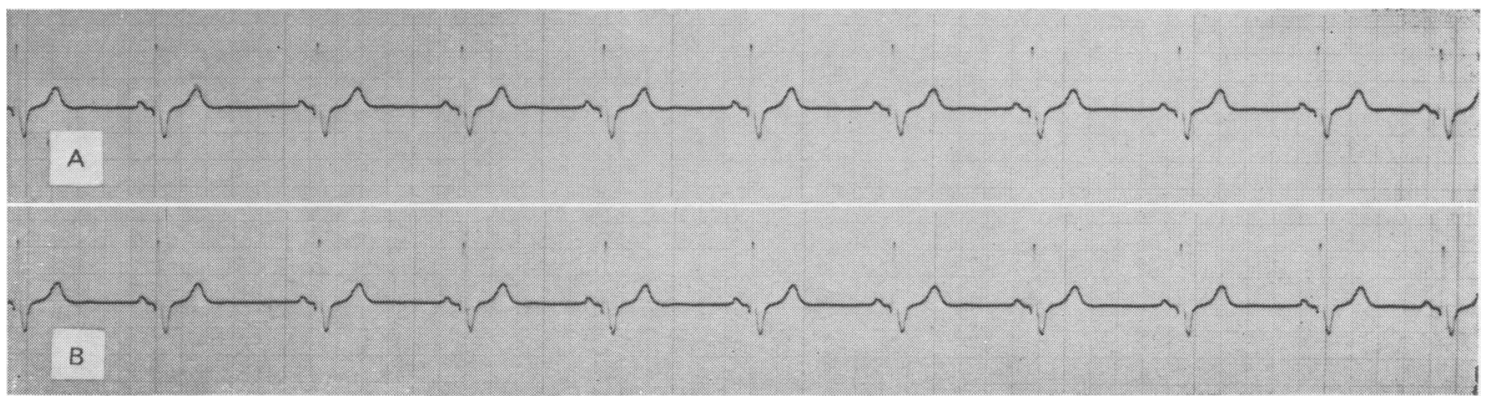

FIG. 11. Simultaneous recording of the ECG. A, recorded at site of attack; B,recorded in the hospital coronary care unit.

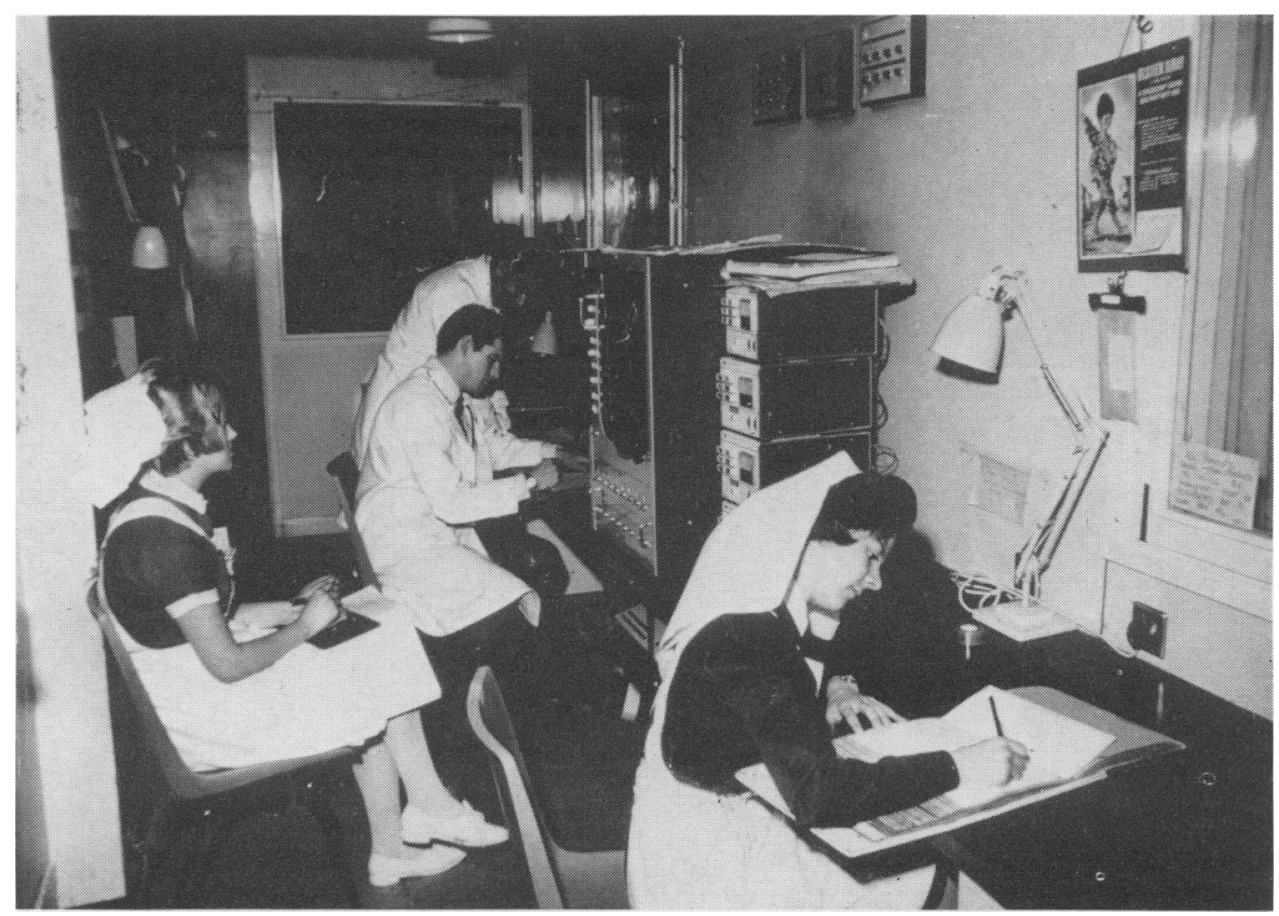

Fig. 12. Central slave oscilloscope in the hospital coronary care unit under continuous surveillance.

repeatedly that in a general medical ward the mortality from myocardial infarction will be unaffected by the provision of bedside monitors, no matter how sophisticated (Rawles \& Crockett, 1969). The alarms tend to be turned off as the number of false alarms are high, thus this warning system is often useless. Coronary care units have reduced mortality when in addition to a bedside monitor a central slave oscilloscope displays the ECG of several patients and is under constant surveillance (Fig. 12). When rhythm disturbances occur the nurse initiates prompt action to prevent the development of lethal dysrhythmias or to correct such dysrhythmias. This monitoring activity of the nurse may of course be undertaken by computational methods.

A ventricular ectopic recognition programme has been written using a digital computer. The single lead electrocardiogram is amplified to $\pm 2-3$ volts and sampled at 250 times/sec. The programme learns on the first two non-ectopic beats received. The RS slope is recognized from the analogue signal coming to the computer. A search backward is then carried out for the peak of the $R$, the $Q$ and beginning of the QRS complex. A search forward is carried out for the $\mathrm{S}$ and end of the QRS. The standard for the R-R interval is noted. The criteria used for ventricular 
ectopic detection include the $\mathrm{R}-\mathrm{R}$ interval, the QRS duration and the direction of the main QRS deflection. The results are displayed numerically on a visual display unit (Fig. 13), or graphically (Fig. 14).

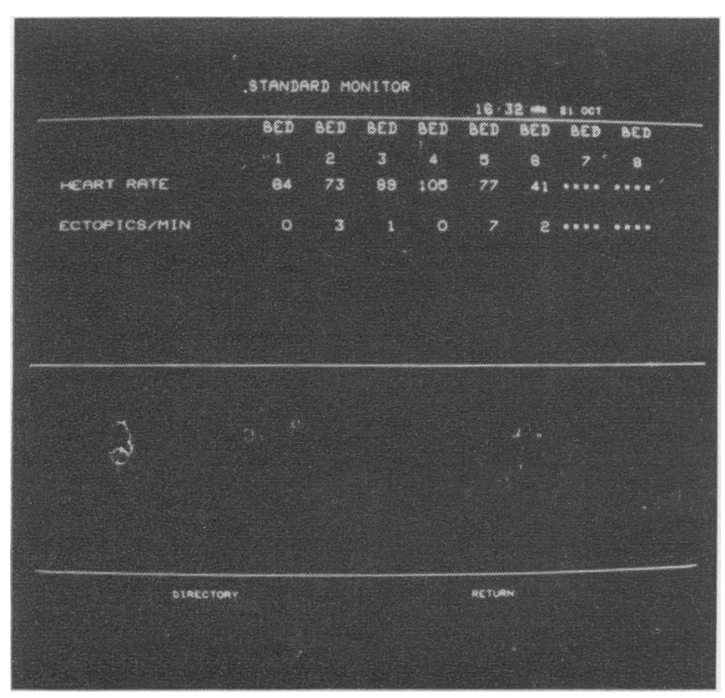

FIG. 13. Visual display unit.

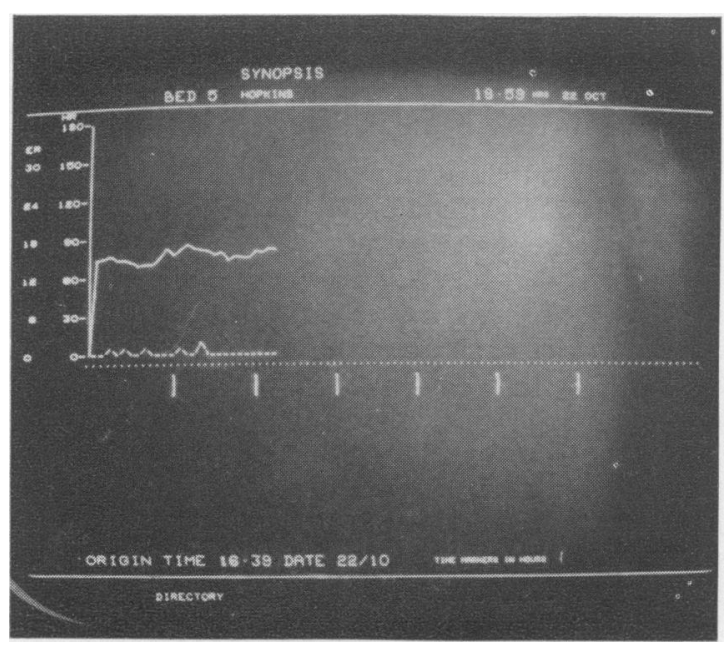

FIG. 14. Graphical representation of heart rate and ectopic count on visual display unit.
Ectopic beats may be recalled and displayed on the visual display unit by means of a light pen. Arterial pressure, cardiac output, oxygen saturation and metabolic parameters may also be monitored.

Since the therapy of cardiogenic shock in patients with acute infarction is at present singularly unrewarding we have concentrated on ECG monitoring with rhythm analysis and the prompt correction of dysrhythmias.

\section{References}

Adgey, A.A.J., Geddes, J.S., Mulholland, H.C., KeEgan, D.A.J. \& PANTRIDGE, J.F. (1968) Incidence, significance and management of early bradyarrhythmia complicating acute myocardial infarction. Lancet, ii, 1097.

Adgey, A.A.J., Nelson, P.G., Scott, M.E., Geddes, J.S., Allen, J.D., Zaidi, S.A. \& Pantridge, J.F. (1969) Management of ventricular fibrillation outside hospital. Lancet, i, 1169.

Bainton, C.R. \& Peterson, D.R. (1963) Deaths from coronary heart disease in persons fifty years of age and younger. A community-wide study. New England Journal of Medicine, 268, 569.

Kuller, L., Lilienfeld, A. \& Fisher, R. (1966) Epidemiological study of sudden and unexpected deaths due to arteriosclerotic heart disease. Circulation, 34, 1056.

MCDonald, E.L. (1968) Coronary Care Units. The London Hospital. In Acute Myocardial Infarction-University of Edinburgh Symposium, p. 29. E. \& S. Livingstone Ltd., Edinburgh and London.

MCNeilly, R.H. \& Pemberton, J. (1968) Duration of last attack in 998 fatal cases of coronary artery disease and its relation to possible cardiac resuscitation. British Medical Journal, 3, 139.

Nixon, P.G.F. (1968) Coronary Care Units and the community. Flying squad services. In Acute Myocardial Infarction-University of Edinburgh Symposium, p. 318. E. \& S. Livingstone Ltd., Edinburgh and London.

PANTRIDGe, J.F. \& Geddes, J.S. (1966) Cardiac arrest after myocardial infarction. Lancet, $\mathbf{i}, 807$.

Pantridge, J.F. \& Geddes, J.S. (1967) A mobile intensive care unit in the management of myocardial infarction. Lancet, ii, 271.

Pantridge, J.F. \& Adgey, A.A.J. (1969) Pre-hospital carethe Mobile Coronary Care Unit. American Journal of Cardiology, 24, 5, 666.

RaWles, J.M. \& Crockett, G.S. (1969) Automation on a general medical ward: Monitron system of patient monitoring. British Medical Journal, 3, 707.

Spiekerman, R.E., Brandenburg, J.T., Achor, R.W.P. \& EDWARDS, J.E. (1962) The spectrum of coronary heart disease in a community of 30,000: clinico-pathologic study. Circulation, 25, 57.

Yater, W.M., Traum, A.H., Brown, W.G., Fitzgerald, R.P., Geisler, M.A. \& Wilcox, B.B. (1948) Coronary artery disease in men eighteen to thirty-nine years of age. Report of eight hundred and sixty-five cases, four hundred and fifty with necropsy examination. American Heart Journal, 36, 334, 481 and 683. 